\title{
CONVERSES OF COPSON'S INEQUALITIES ON TIME SCALES
}

\author{
S. H. SAKer, D. O’REgAn And R. P. AgArwal
}

Abstract. In this paper, we will prove some new dynamic inequalities on a time scale $\mathbb{T}$. These inequalities when $\mathbb{T}=\mathbb{N}$ contain the discrete inequalities due to Bennett and Leindler which are converses of Copson's inequalities. The main results will be proved using the Hölder inequality and Keller's chain rule on time scales.

Mathematics subject classification (2010): 26A15, 26D10, 26D15, 39A13, 34A40. 34N05.

Keywords and phrases: Hardy's inequality, Leindler's inequality, time scales.

\section{REFERENCES}

[1] A. Aikawa And M. Essén, Potential Theory-Selected Topics, Lecture Notes in Math. 1633, Springer-Verlag, Berlin (1996).

[2] G. Bennetr, Some elementary inequalities, Quart. J. Math., Oxford (2), 38 (1987), 401, 425.

[3] G. Bennett, Some elementary inequalities II, Quart. J. Math. 2 (1988), 385-400.

[4] P. R. Bess ACK, Hardy's inequality and its extensions, Pacific J. Math. 11 (1961), 39-61.

[5] M. Bohner And A. Peterson, Dynamic Equations on Time Scales: An Introduction with Applications, Birkhäuser, Boston, 2001.

[6] M. Bohner, A. Peterson, Advances in Dynamic Equations on Time Scales, Birkhäuser, Boston, 2003.

[7] E. T. Copson, Note on series of positive terms, J. London. Math. Soc. 2 (1927), 9-12.

[8] E. T. Copson, Note on series of positive terms, J. London. Math. Soc. 3 (1928), 49-51.

[9] E. T. Copson, Some integral inequalities, Prof. Roy. Soc. Edinburg. Sect. A 75 (1975/1976), 157164.

[10] E. B. ELLIOTT, A simple expansion of some recently proved facts as to convergency, J. London Math. Soc. 1 (1926), 93-96.

[11] G. H. HARDY, Notes on a theorem of Hilbert, Math. Z. 6 (1919), 314-317.

[12] G. H. HARDY, Notes on some points in the integral calculus, Messenger Math. 54 (1925), 150-156.

[13] G. H. HARDY, Notes on some points in the integral calculus, Messenger Math. 57 (1928), 12-16.

[14] G. H. Hardy, J. E. Littlewood and G. Polya, Inequalities, 2nd Ed. Cambridge Univ. Press 1952.

[15] S. HiLger, Analysis on measure chains - a unified approach to continuous and discrete calculus, Results Math. 18 (1990) 18-56.

[16] M. Izumi And S. Izumi, On some inequalities for Fourier Series, J. D’Analyse Math. 21 (1968), 277-291.

[17] S. Kaijser, L. Nikolova, L. E. Persson And A. Wedestig, Hardy-type inequalities via convexity, Math. Ineq. Appl. 8 (2005), 403-417.

[18] S. Kaijser, L. E. Persson And A. ÖBerg, On Carleman and Knopp's inequalities, J. Approx. Theor. 117 (2002), 140-151.

[19] A. Kufner And Lars-Erik Persson, Weighted Inequalities of Hardy Type, World Scientific Publishing (2003).

[20] A. Kufner, L. Maligranda and L. Persson, The Hardy inequalities: About its History and Some Related Results, Pilsen (2007).

[21] L. LEINDLER, Some inequalities pertaining to Bennett's results, Acta Sci. Math. (Szeged), 58 (1993), 261-279. 
[22] L. LEINDLER, Further sharpening of inequalities of Hardy and Littlewood, Acta Sci. Math. (Szeged), 54 (1990), 285-289.

[23] N. Levinson, Generalizations of an inequality of Hardy, Duke Math. J. 31 (1964), 389-394.

[24] J. A. Oguntuase AND C. O. IMORU, New generalizations of Hardy's integral inequalities, J. Math. Anal. Appl. 241 (2000), 73-82.

[25] J. A. Oguntuase and E. O. Adeleke, On Hardy's integral inequality, Facta Univ. (NIS), Ser. Math. Infor. 20 (2005), 9-20.

[26] B. OpIC And A. Kufner, Hardy-type inequalities, Longman Scientific\& Technical, Harlow, UK, (1989).

[27] U. M. OzKan And H. Yildirim, Hardy-Knopp-type inequalities on time scales, Dyn. Sys. Appl. 17 (2008), 477-486.

[28] B. G. PAChPATte, A note on certain inequalities related to Hardy's inequality, Indian J. Pure Appl. Math 23 (1992), 773-776.

[29] S. H. SAKER, Lyapunov's type inequalities for fourth order differential equations, Abst. Appl. Anal. (accepted).

[30] M. R. Sidi, A. F. M. TorRes, Hölder's and Hardy's two dimensional diamond-alpha inequalities on time scales, Annales of Univ. Craiva, Math. Comp. Series 37 (2010), 1-11.

[31] A. Tuna And S. Kutukcu, Some integrals inequalities on time scales, Appl. Math. Mech. Eng. Ed. 29 (2008), 23-29. 